\title{
Personality Traits, Burnout, and Emotional Labor Correlation among Teachers in Pakistan
}

\author{
Amna Khalil1, Muhammad Majid Khan', Muhammad Ali Raza1, Bahaudin G. Mujtaba ${ }^{2 *}$ \\ ${ }^{1}$ COMSATS Institute of Information Technology, Islamabad, Pakistan \\ ${ }^{2}$ Nova Southeastern University, Fort Lauderdale, FL, USA \\ Email:amna_khalil1@ymail.com,majidkhan799@comsats.edu.pk,m.aliraza@com sats.edu.pk, ^mujtaba@nova.edu
}

How to cite this paper: Khalil, A., Khan, M.M., Raza, M.A. and Mujtaba, B.G. (2017) Personality Traits, Burnout, and Emotional Labor Correlation among Teachers in $\mathrm{Pa}$ kistan. Journal of Service Science and Management, 10, 482-496.

https://doi.org/10.4236/jssm.2017.106038

Received: November 15, 2017

Accepted: December 8, 2017

Published: December 11, 2017

Copyright () 2017 by authors and Scientific Research Publishing Inc. This work is licensed under the Creative Commons Attribution International License (CC BY 4.0).

http://creativecommons.org/licenses/by/4.0/

\begin{abstract}
The main purpose of this research is to study the impact of personality on job burnout among educators. Additionally the role of emotional labor on the relationship of personality and burnout is also investigated. In this model, job burnout (exhaustion, depersonalization and lack of personal accomplishment) is a dependent variable; personality (extraversion, neuroticism, agreeableness, openness to experience and conscientiousness) is an independent variable, while emotional labor (surface acting and deep acting) is a mediating variable. To investigate the relationship among above stated variables, correlation and multiple regression analysis were conducted. Questionnaires were used to collect the data from 199 secondary level teachers of private schools. The results of correlation and multiple regression showed the negative impact of personality on burnout, positive impact of personality on emotional labor, and the negative impact of emotional labor on job burnout. Discussion, suggestions, implications, and recommendations selection and training are provided.
\end{abstract}

\section{Keywords}

Personality Traits, Emotional Labor, Job Burnout, Teachers, Big Five

\section{Introduction}

Due to globalization and intensive competition, managers and executives of almost all sectors including the educational sector are facing the prospects of burnout. Burnout can have negative impacts both on individuals as well as organizations. With respect to individuals, burnout can cause physical as well as psychological illnesses (Mujtaba and McCartney, 2007) [1]. Research has consistently demonstrated that burnout is positively related to increased turnover, in- 
creased absenteeism and decreased performance (Riolli \& Savicki, 2006) [2]. As such, it is important to study burnout in the education sector so administrative leaders and professionals can strategically create a better work environment for effective job performance (King and Haar, 2017) [3].

Burnout was first introduced by Freudenberger (1974) [4]. From 1974 until the present, many researchers have made a valuable contribution in the field of burnout (Freudenberger, 1974 [4]; Maslach \& Jackson, 1981) by focusing on its causes and consequences [5]. The consequences of burnout may be increased absenteeism, reduced performance, poor productivity and more intentions of turnover (Maslach \& Leiter, 2005) [6]. Personality has also been studied by many researchers in order to understand its impact on burnout (Zeng \& Shi, 2006 [7]; Lamb, 2009) [8]. Over the last two decades, researchers investigated the impact of individual differences on burnout (i.e. personality) because, unlike stress, burnout may not be experienced by every individual (Mujtaba and McCartney, 2007) [1]. Though many researchers studied the impact of personality on burnout, the role of personality especially big five personality traits on burnout is still controversial. Researchers have called for studies in the educational sector to address the issue of occupational stress and burnout (Kyriacou, 2001) [9]. Personality is found as an important predictor of burnout (Evers, Tomic, \& Brouwers, 2005 [10]; Hakanen, Bakker, \& Schaufeli, 2006) [11] and it needs to be investigated more extensively in the educational sector across diverse populations around the globe (Cano-Garcia, Padilla-Munoz, \& Carrasco-Ortiz, 2005) [12]. Emotional labor has also received attention in relation to burnout as well as individual differences, i.e. personality traits. The expression "emotional labor" was first introduced by Hochschild in 1983 [13]. Emotional labor refers to the expression of emotions which are in line with the emotions expected by organizations to express (Hochschild, 1983) [13]. Bono and Vey (2005) [14] revealed an association between emotional labor and exhaustion (stress dimension of burnout). Due to the intense competitive work environment, organizations are now focusing on the emotional regulation of their employees (Diefendorff \& Richard, 2003) [15].

Researchers and practitioners are equally interested in the concept of emotions at work and emotional labor (Cartwright \& Pappas, 2007) [16]. But the demand of emotional labor is high in the jobs in which continuous face-to-face or voice-to-voice interaction is required for service providers and customers (Pizam, 2004) [17]. Teachers are supposed to interact with their students for long periods each day and it may suggest that demand of emotional labor is high in the educational arena. Researchers suggested conducting research to deeply know the process of emotional labor in order to control its negative outcomes as well as burnout (Johnson \& Spector, 2007) [18].

Educational sector is one of the service sectors and teachers are one of the important service providers to students. Therefore, this study investigates the impact of personality on burnout and the mediating role of emotional labor in teachers. High levels of burnout and emotional exhaustion have been found in 
the teaching profession (Hakanen et al., 2006) [11]. However, further research is required to examine emotional labor (Diefendorff \& Richard, 2003) [15]. Emotional labor is very much important and required in teaching profession due to the complexity in the relationship between teacher and student (Sutton, 2007) [19]. From 1980 to 1990s, research in the field of burnout mainly focused on the human service jobs including in the healthcare and education sectors in the Western hemisphere. This suggests that investigating burnout in teachers is important and should be extended to the rest of world, especially in South Asia where such specific empirical studies are lacking. Evans and Fischer (1993) found all the three dimensions of burnout were present in teachers [20].

\section{Theory and Hypothesis Development}

\section{Association between Personality and Burnout}

Cano-Garcia, Padilla-Munoz and Carrasco-Ortiz (2005) [12] confirmed that highly neurotic and introvert teachers experience high levels of burnout. Individuals who have openness to experience personality become less emotionally exhausted in stressful situations (Zimmerman, 2008) [21]. Open individuals are less likely to suffer from lack of personal accomplishment because having such a personality helps them maintain a positive view towards things. It suggests that individual high in openness may not experience burnout. Figure 1 provides an overview model of the variables involved and their relationship in this study.

Extraverts may not experience as much burnout as compared to introverts because they are more sociable and optimistic. Extroversion is negatively related to emotional exhaustion (Zellars et al., 2000) [22], and it suggests that individual having high extraversion personality will experience less burnout. Individuals having high agreeableness personality will experience less burnout. Because of personality traits like affection and kindness, agreeable people tend to have a positive view about negative features of their work environment (Zimmerman, 2008) [21]. The four dimensions (Openness, Extraversion, Agreeableness, and Conscientiousness) of personality are negatively associated with burnout while neuroticism (negative in traits) is positively associated with burnout. Overall, existing literature confirms that if one's personality is positive and strong, then burnout may be low.

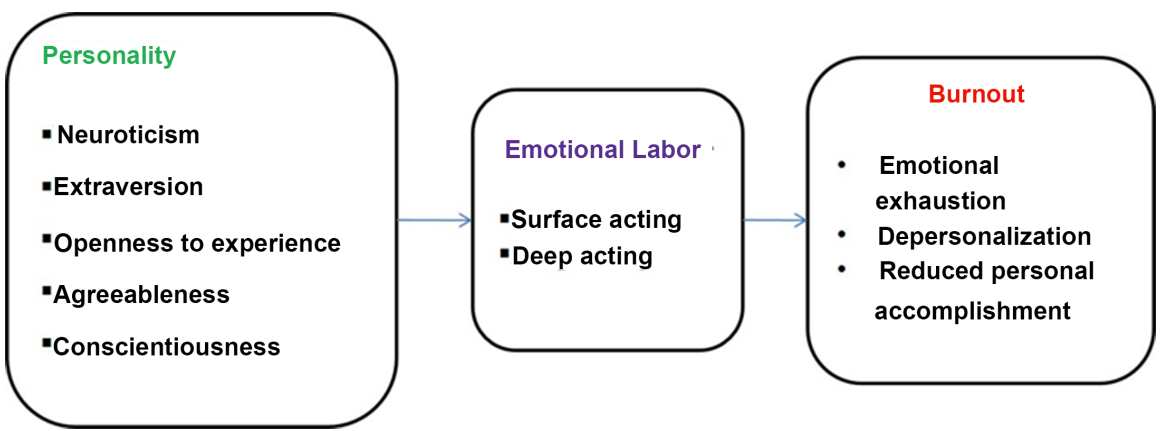

Figure 1. The link between personality, emotional labor and burnout model. 


\section{The Job Demand Resource Theory (JD-R)}

In pertinent literature, the Demand Resource theory $(J D-R)$ is used to explain burnout. Under the umbrella of $J D-R$ theory if job demand increases then individuals may be more likely to feel burnout because they have to put more physical and mental efforts to meet the demands. When the resources related to job like autonomy, empowerment, personality and support are sufficient to meet the job demands, then this will be more likely to reduce burnout (Schaufeli \& Bakker, 2004) [23]. Lack of resources required to meet the demands of job may cause the sense of lack of personal accomplishment among individuals (Maslach et al., 2001) [24]. Personality is one of the personal resources (Bakker et al., 2006) [25]. This shows that if one has a strong personality it would help in reducing burnout because personality is one of the personal resources. Therefore, the Job Demand-Resource theory also supports the assumptions of researchers, i.e. positive/strong personality may reduce the chances of burnout while the people with negative/weak personality are more at the risk of experiencing burnout.

\section{$\mathrm{H} 1$ : Personality is negatively associated to burnout.}

\section{Association between Personality and Emotional Labor}

Diefendorff and colleagues (2005) revealed the positive relation of Neuroticism, Conscientiousness, Agreeableness, and Extraversion with surface acting. Moreover they found a positive relation of only Agreeableness with deep acting [26]. Among all five dimensions, Neuroticism is found to be strongly associated with surface acting and agreeableness is strongly associated with deep acting (Austin et al., 2008 [27]; Diefendorff et al., 2005) [26]. Shin and colleagues (2006) argued that performance of emotional labor may have both positive and negative results based on personality and individual differences [28]. Kim (2008) proposed that Neuroticism has a significant association with surface acting while Extraversion with deep acting [29]. Shin et al. (2006) maintained that all four dimensions of personality excluding neuroticism are positively associated with deep acting [28]. Some researchers maintained contrasting results but majority have found personality has positive relationship with emotional labor.

The literature shows that four dimensions of personality has a positive relationship with deep acting while neuroticism has positive relations with surface acting. Deep acting is a genuine acting while surface acting is a fake one. Therefore researchers assume that if one has a positive and strong personality, then he/she will be more likely to act genuinely and thus emotional labor will be strong. If one has a negative and weak personality, then he/she will be less likely to act genuinely and, consequently, emotional labor will be weak.

H2: Personality is positively associated to emotional labor.

\section{Association between Emotional Labor and Burnout}

Grandey et al. (2012) revealed that deep acting is positively associated to increased job satisfaction [30], and increased personal accomplishment (Cheung \& Tang, 2010) [31]. Surface acting is positively related with emotional exhaustion (Montgomery et al., 2006 [32]; Bono \& Vey, 2005 [14]; Grandey et al., 2012) [30]. It is also found that surface acting may cause negative health and job out- 
comes as well as cause burnout (Beal et al., 2006 [33]; Naring, Briet, \& Brouwers, 2006) [34]. Naring et al. (2006) found positive association of surface acting with exhaustion in teachers but they didn't find any positive association between deep acting and burnout. Therefore, researcher may assume that the more strong the emotional labor, the less the chances of burnout will be If one will act genuinely (i.e. deep acting) he/she will be less likely to experience emotional dissonance because the internal emotions will be aligned to displayed emotions, resultantly burnout will be low and vice versa [34].

H3: Emotional labor is negatively associated to burnout.

\section{Association between Personality, Emotional Labor and Burnout}

Nejat, Memduh and Rukiye (2013) studied the impact of teacher's personality traits on their emotional exhaustion in a mediating model which centers on emotional labor [35]. Neuroticism and extraversion were found to significantly influence emotional exhaustion whereas other dimensions of personality were not found to be predictive of emotional exhaustion. In general, personality traits were found to predict emotional labor and all dimensions of emotional labor were found to affect emotional exhaustion. Further, findings of mediation analysis showed that surface acting was the only mediator in the relationship between neuroticism and emotional exhaustion. Kiffin-Petersen, Jordan and Soutar (2011) revealed that emotional labor mediates the relationship of personality with exhaustion and citizenship behavior [36]. Findings showed that emotionally unstable individuals are more engaged in surface acting and more likely to feel exhaustion (burnout). While agreeable individuals and extroverts are more linked to deep acting which is negatively associated with exhaustion (burnout).

H4: Emotional labor mediates the relationshiplassociation between personality traits and job burnout.

\section{Methodology}

The questionnaire based survey technique was used for current study. Survey was conducted in educational sector.

We employed the "multistage-random sampling" which is comprised of multiple stages. Simple, cluster or stratified random sampling is used at each stage to divide a large population into small segments. We used simple random sampling for selecting schools and then selecting teachers among the selected schools. Among all 44 private secondary schools registered with Rawalpindi board in Pakistan, we randomly selected 40 schools which were deemed appropriate (Sekaran, 2003, p. 294) [37]

Relevant permission for data collection was obtained. In social sciences, a response rate of more than $30 \%$ is good and appropriate (Sekaran, 2006) [38]. In this study, our response rate was $32.5 \%$. The total population of 13 randomly selected schools is 400 and our sample size is 199 (Sekaran, 2003, p. 294) [37]. We distributed 250 questionnaires among secondary school teachers of 13 randomly selected schools. A total of 199 completed questionnaires were given back which 
generates $79.6 \%$ response rate.

The construct of Big Five Personality Traits was measured by the Costa and McCrae (1985) [39]: "I see myself as someone who is curious about many different things." The construct of Emotional Labor was measured by the items from Kruml-Geddes Emotional Labor (2000): "When working with students, I attempt to feel certain emotions that my institution wants me to express." [40] The construct Burnout was measured by adopting items from The Maslach Burnout Inventory (MBI) (Maslach, Jackson, \& Leiter, 1996): "I feel emotionally drained from my work." [41] The construct of Personality, Emotional Labor and Burnout were measured through 25, 10 and 17 items respectively. The 5-point Likert scale is used to collect responses for all three constructs i.e. 1) "strongly disagree"; 2) "disagree"; 3) "neither agree nor disagree"; 4) “agree"; 5) "strongly agree". Chronbach alpha for personality, emotional labor and burnout was $0.889,0.760$ and 0.666 respectively.

\section{Analysis}

Descriptive statistics showed the values of mean as well as standard deviation. All variables were assessed on a 5-point Likert scale so range lies between minimum 1 to maximum 5 . Table 1 show that the mean value of personality, emotional labor and burnout was 3.5, 3.1 and 3.0 respectively. Highest mean was of "Personality" $(M=3.5)$, while lowest mean was of "Burnout" $(M=3.0)$. Value for personality is 0.56 , the value for emotional labor is 0.65 and the value for burnout is 0.48 .

Correlation analysis was used to test the relationship and association between variables. The value of coefficient of correlation for all construct for the present study is shown in Table 2 . The correlation between personality and emotional labor is positive and significant at $\mathrm{p}<0.01 ; \mathrm{r}=0.577^{\star \star}$. The Correlation between personality and burnout is negative which is significant at $\mathrm{p}<0.01 ; \mathrm{r}=-0.311^{\star *}$. The correlation between burnout and emotional labor is negative and significant at $\mathrm{p}<0.01 ; \mathrm{r}=-0.305^{\star *}$.

Table 1. Descriptive statistics.

\begin{tabular}{cccc}
\hline Variables & $\mathrm{N}$ & Mean & Std. Deviation \\
\hline Personality & 199 & 3.5 & 0.56 \\
Emotional labor & 199 & 3.1 & 0.65 \\
Burnout & 199 & 3.0 & 0.48 \\
\hline
\end{tabular}

Table 2. Correlation results.

\begin{tabular}{lccc}
\hline \multicolumn{1}{c}{ Variables } & 1 & 2 & 3 \\
\hline 1) Personality & 1.00 & & \\
2) Emotional labor & $0.577^{* *}$ & 1.00 & \\
3) Burnout & $-0.311^{* *}$ & $-0.305^{\star *}$ & 1.00 \\
\hline
\end{tabular}

**: Correlation is significant at the 0.01 level (2-tailed). 
Table 3 shows the regression results for testing the hypothesis. Personality is negatively related with burnout as $\mathrm{B}=-0.241$ which is significant at $\mathrm{p}<0.001$. The value of adjusted $r$ square shows that the $94.7 \%$ in burnout is explained by personality. So based on this, $\mathrm{H} 1$ is accepted that personality is negatively related with burnout. $\mathrm{H} 2$ states that personality is positively related with emotional labor and we see that $\mathrm{B}=0.530$ which is significant at $\mathrm{p}<0.001$. The value of adjusted $\mathrm{r}$ square shows that $72.3 \%$ variation in emotional labor is explained by personality. So based on this, $\mathrm{H} 2$ is accepted that personality is positively related with emotional labor. H3 explains the relationship between emotional labor and burnout. The value of adjusted $r$ square shows that $93.2 \%$ variation in burnout is explained by emotional labor, which is significant at $\mathrm{B}=-0.270, \mathrm{p}<0.001$, so based on this $\mathrm{H} 3$ is accepted that emotional labor is negatively related with burnout.

To examine the effect of emotional labor between personality and burnout, a three step regression analysis is used as suggested in previous research studies (Baron \& Kenny, 1986) [42]. In Table 4, the first step, which is the effect of personality on burnout, is taken into account; the relationship is significant at $\mathrm{p}<$ 0.001 , which states that personality has a significant negative effect on burnout. In the second step, the effect of personality on emotional labor is taken into account, the relationship is significant $(\mathrm{p}<0.000)$, which implies that personality has a significant positive effect on emotional labor. In the third step, both personality and emotional labor are predicting burnout. In this step, the value of emotional labor demonstrates that the effect of emotional labor is statistically significant at $\mathrm{p}<0.01$. Here the regression coefficients for personality are not only decreasing in magnitude but also became insignificant $(B=-0.136, p>$ 0.05), which implies that emotional labor is mediating the relationship between personality and burnout.

\section{Discussion}

Some organizations and their workers are continually plagued by burnout. The results of this study showed that personality is related with all three dimensions of burnout. Additionally, the mediating role of emotional labor is also found. Anvari, Kalali and Gholipour (2011) also found negative association of extraversion and job burnout, negative association of agreeableness and job burnout, positive association of neuroticism and job burnout while negative

Table 3. Regression analysis.

\begin{tabular}{ccccc}
\hline Hypothesis & $\mathrm{P}$ & $\begin{array}{c}\text { Adjusted } \mathrm{R} \\
\text { square }\end{array}$ & $\begin{array}{c}\text { Standardized } \\
\text { coefficients } \beta\end{array}$ & $\mathrm{T}$ \\
$\mathrm{H} 1 \mathrm{P} \longrightarrow \mathrm{B}$ & 0.001 & 0.053 & -0.241 & 3.479 \\
$\mathrm{H} 2 \mathrm{P} \longrightarrow \mathrm{EL}$ & 0.000 & 0.277 & 0.530 & 8.775 \\
$\mathrm{H} 3: \mathrm{EL} \longrightarrow \mathrm{B}$ & 0.000 & 0.068 & -0.270 & 3.937 \\
\hline
\end{tabular}

Note: ${ }^{* * *} \mathrm{p}<0.001$. 
Table 4. EL act as a mediator between $\mathrm{P}$ and $\mathrm{B}$.

\begin{tabular}{cccccccc}
\hline Steps & $\begin{array}{c}\text { Dependent } \\
\text { variable }\end{array}$ & $\begin{array}{c}\text { Independent } \\
\text { variable }\end{array}$ & $\begin{array}{c}\text { Standardized } \\
\text { regression } \\
\text { coefficients }\end{array}$ & $\mathrm{F}$ & $\mathrm{T}$ & Sig. & $\begin{array}{c}\text { Adjusted } \\
\mathrm{R}^{2}\end{array}$ \\
\hline 1 & $\mathrm{~B}$ & $\mathrm{P}$ & -0.241 & 12.106 & 3.479 & 0.001 & 0.053 \\
2 & $\mathrm{EL}$ & $\mathrm{P}$ & 0.530 & 77.007 & 8.775 & 0.000 & 0.277 \\
3 & $\mathrm{~B}$ & $\mathrm{P}$ & -0.136 & 9.237 & 1.683 & 0.094 & 0.077 \\
& & $\mathrm{EL}$ & -0.198 & & 2.461 & 0.015 & \\
\hline
\end{tabular}

$\mathrm{B}=$ burnout; $\mathrm{EL}=$ emotional labor; $\mathrm{P}=$ personality.

association of openness and job burnout [43]. Other studies and findings on extraversion, agreeableness and neuroticism also support our results (Alarcon et al., 2009; Bowling et al., 2004) [44].

The purpose of this research was to explain the relationship between personality and burnout of teachers (emotional exhaustion, depersonalization and lack of personal accomplishment). Similarly, the effect of emotional labor on the relationship of personality and burnout is investigated. The main research question of the study was: to what extent personality has an impact on an employee's burnout? Data was collected from participants working as secondary school teachers in private schools through self-reported questionnaires.

Results of data analysis revealed many appealing and remarkable findings. The results of multiple regression analysis demonstrated that personality has a significant negative association with burnout. Findings also showed that personality explains $92 \%$ variance in "burnout". A significant negative association between personality and "burnout" is found. Moreover, a significant positive relationship between personality and emotional labor is found. Personality explained the variation by $21.23 \%$ to the EL (emotional labor). A negative relationship is found between EL and burnout (B). EL explained the variation by 92\% to B (see Figure 2).

The result demonstrates a significant negative relationship between personality and burnout. On the basis of research findings, it is stated that personality plays vital role in reducing burnout. Our research supports that personality is a strong predictor of burnout. Similarly, Swider and Zimmerman (2010) revealed the importance of individual difference in predicting job burnout [45]. Goddard et al. (2004) gave somewhat similar justification that there is an obvious relationship between burnout and personality [46]. Our results suggest that burnout of the employees could be minimized if an organization considers the personalities of its employees when initially hiring them.

Neurotic individuals include features like anxiety, anger, hatred, depression, inconsideration and thoughtlessness (Mujtaba and McCartney, 2007) [1]. Neuroticism is a type of personality which is negative in traits. Previous researches proved a positive relation of neuroticism and burnout (Madnawat \& Metha, 2012; Cano-Garcia, Padilla-Munoz \& Carrasco-Ortiz, 2005 [12]; Zellars et al., 2000) [22]. It provides supports to the above stated hypothesis that if personality 


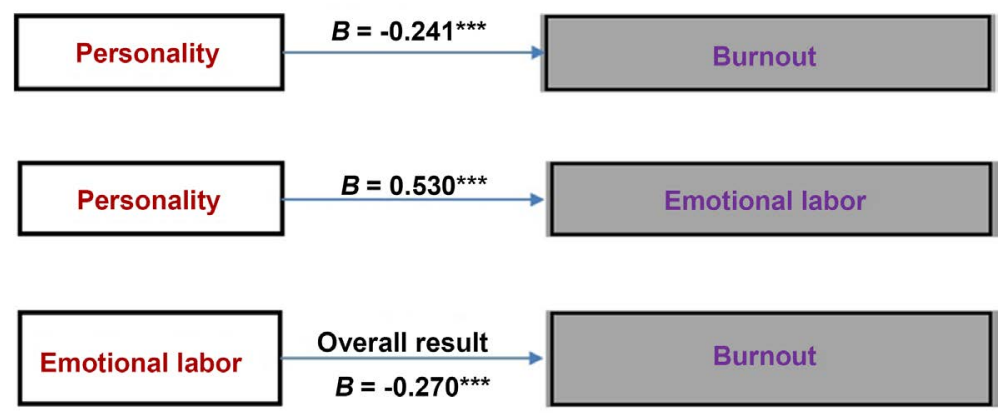

Figure 2. Relationship between independent and dependent variable.

would be negative burnout will be more while if the personality is positive then burnout level will be low.

Among five dimensions of personality, neuroticism is the negative personality while the other four are positive traits. Agreeableness refers to individuals who have more positive traits like trust, affection and kindness. Agreeable individuals are less likely to feel burnout because of their understanding about the negative aspects of work and their positive approach towards their jobs (Zimmerman, 2008) [21].

Openness refers to people who are open to new insights and views (Mujtaba, 2014) [47]. A negative relationship is found between openness and burnout (Ghorpade et al., 2007, 2011) [48] [49]. Previous researchers also found a negative association of extroversion and burnout (Francis, Louden \& Rutledge, 2004) and a negative association between conscientiousness and burnout (Lepine, Lepine \& Jackson, 2004) [50].

So these studies provide evidence that if one's personality is positive then the chances of burnout will be less.

Furthermore, our results indicated a positive relationship between personality and emotional labor. It means that if the personality is positive, then emotional labor will be genuine/strong (deep acting), while if personality is negative then emotional labor will be fake/weak (surface acting). Literature supports this finding that there is a positive relationship between neuroticism and surface acting while negative relations with deep acting. Extroversion is positively associated with deep acting and negatively associated with surface acting. Diefendorffet $e t$ al. (2005) revealed the positive relation of deep acting with conscientiousness while negative relation of surface acting with conscientiousness [26]. Agreeable individuals tend to opt for deep acting because they are good in regulating their emotions (Tobin, Graziano, Vanman, \& Tassinary, 2000) [51].

Furthermore, negative relationship is found between emotional labor and burnout. It means that if emotional labor is genuine/strong, then burnout will be low while if the emotional labor is weak/fake (surface acting) burnout will be high. Meta-analysis (Bono \& Vey, 2005) revealed that surface acting is positively correlated with burnout because individuals only fake the desired emotion on the surface rather than to modify them internally [14]. Surface acting leads to 
more emotional dissonance which increases the chances of burnout (Martínez-Inigo, Totterdell, Alcover, \& Holman, 2007) [52]. Martínez-Inigo et al. (2007) found a positive relation of surface acting with burnout, while a negative relation of deep acting with burnout [52].

Finally, this study investigated the role of emotional labor between personality and burnout. It is proved that emotional labor acts as a mediator between personality and burnout. Kiffin-Petersen [36], Jordan and Soutar (2011) also gave similar justification. Findings revealed that emotionally unstable individuals are more engaged in surface acting and more likely to feel exhaustion (burnout) [36]. Agreeable individuals and extroverts are more inclined to deep acting which is negatively associated with exhaustion (burnout).The present study proved that individuals with strong/positive personality are more inclined to opt for deep acting, and are resultantly less likely to experience emotional dissonance and burnout. Individuals with negative/weak personality are more likely to opt for surface acting, and resultantly are more likely to experience emotional dissonance and burnout.

\section{Limitations and Implications}

Due to various limitations, the findings of this research cannot be generalized. The results of this research are more persuasive rather than definitive because of following limitations.

Personality, emotional labor and burnout were measured through the self-reported questionnaires. Respondents for the current study were secondary school teachers from thirteen private schools, so the results cannot be generalized to secondary school teachers of all private schools.

Another limitation for current study is time and cost constraint. The generalization of research can be increased with more time and financial resources. More financial resources and time will allow including private schools of other nearby cities in the region. The current research only includes the private schools; further research can be done in order to include the public schools. Comparative study between public and private schools is also recommended for future research.

The present study is cross sectional in nature and limited as changes occur in emotional labor styles with the passage of time. Longitudinal studies are required to investigate the possibility of a causal relationship between personality traits and burnout.

Time of the study can play an important role as the teaching burden changes with time and burnout levels might vary at the start of the year, mid-year or the ending of the year. More richness in results can be added if the sample is further categorized by age and gender. Finally, generalization of results would be better in case of larger sample size. Larger sample size can be chosen to investigate the effects of big five personality traits on a teacher's burnout in other types of schools such as public sector schools. An important aspect as emotional intelli- 
gence may also be taken into consideration. These variables might have some reflection or association with burnout. Other individual level predictors of job burnout may be investigated, such as cognitive ability, gender, and age. Other possible mediators of this relationship can also be taken into consideration, such as work environment. Longitudinal studies may be conducted to investigate the chances of a causal association between personality and burnout.

We recommend conducting longitudinal studies to investigate the relationship between personality and burnout as most of the studies which investigated burnout are cross sectional in nature. The rationale behind the recommendations is that longitudinal studies would help to understand the temporal changes in burnout which are predicted by personality. Researchers may investigate which personalities experience varying degree of burnout over the passage of time.

We also recommend for researchers to examine the moderators between personality and burnout. For example work environment may be one of the moderators between personality and burnout because in highly stressful situations all employees feel burnout regardless of personality type. In such situations burnout becomes inevitable for all employees. The relationship between personality and burnout becomes weak in truly stressful situations. So, further research can be conducted to investigate possible moderators between personality and burnout.

With respect to practitioners, this study may help to identify the personalities which are more prone to burnout because it has various negative work outcomes (i.e. absenteeism, turnover and reduced performance/performance).

Halbesleben, Osburn, and Mumford (2006) revealed burnout can be identified through staffing and selection procedures [53]. Organizations may benefit from using the big five model of personality in selection of employees, as they may test their personalities to know if they have the personality which is more prone to burnout or not.

This research makes a significant contribution to the literature of burnout by indicating the role of personality and emotional labor in employee's burnout in the educational sector. This study is helpful in order to implement secondary level prevention programs against burnout by considering which personality is more prone to burnout.

The findings revealed that, despite of using burnout prevention programs, some employees will experience burnout due to their specific personality traits. So, management must focus on personality testing in order to identify which personalities are more prone to burnout. Consequently, management may provide relevant training and education to qualified candidates so they can effectively deal with stressful situations and assignments in the workplace.

\section{Conclusions}

The findings of current study increases our understanding about burnout, as well as the theoretical base of big five personality traits and how it affects job 
burnout of teachers. Additionally, it examined how burnout level of teachers alters when they are required to exercise emotional labor on their jobs.

Research findings revealed that management of schools should pay attention to and identify which type of personality employees have at the time of selection and recruitment, as this will help in decreasing turnover and cost at later stages because employees having negative personalities are more prone to burnout.

Finally, findings also suggest that emotional labor plays a mediating role between personality and burnout. It suggests that individuals with positive personality traits are more inclined towards deep acting. Deep acting reduces emotional dissonance because of no difference between felt emotions and those externally displayed. Resultantly such individuals are less likely to feel burnout. Individuals with negative personality traits are more likely to opt for surface acting. Surface acting increases the emotional dissonance because of difference between felt emotions and those externally displayed. Resultantly such individuals are more likely to feel and experience burnout. Overall, once the personality traits of existing educators are identified, then relevant training and development programs can be implemented to reduce burnout and the negative implications of emotional labor in the workplace.

\section{References}

[1] Mujtaba, B.G. and McCartney, T. (2007) Managing Workplace Stress and Conflict amid Change. Llumina Press, Davie, Florida.

[2] Riolli, L. and Savicki, V. (2006) Impact of Fairness, Leadership, and Coping on Strain, Burnout and Turnover in Organizational Change. International Journal of Stress Management, 13, 351-377. https://doi.org/10.1037/1072-5245.13.3.351

[3] King, E. and Haar, J.M. (2017) Mindfulness and Job Performance: A Study of Australian Leaders. Asia-Pacific Journal of Human Resources, 55, 298-319. https://doi.org/10.1111/1744-7941.12143

[4] Freudenberger, H.J. (1974) Staff Burn-Out. Journal of Social Issues, 30, 159-165. https://doi.org/10.1111/j.1540-4560.1974.tb00706.x

[5] Maslach, C. and Jackson, S.E. (1981) The Measurement of Experienced Burnout. Journal of Occupational Behavior, 2, 99-113. https://doi.org/10.1002/job.4030020205

[6] Maslach, C. and Leiter, M.P. (2005) Stress and Burnout: The Critical Research. In: Cooper, C.L., Ed., Handbook of Stress Medicine and Health, 2nd Edition, CRC Press, London, 153-170.

[7] Zeng, C.K. and Chi, K. (2006) Relationship of Big Five Personality with Employees' Job Burnout. Chinese Journal of Clinical Psychology, 15, 614-616.

[8] Lamb, S. (2009) Personality Traits and Resilience as Predictors of Job Stress and Burnout among Call Center Employees. Master's Thesis, Bloemfontein University, Bloemfontein.

[9] Kyriacou, C. (2001) Teacher Stress: Directions for Future Research. Educational Review, 53, 27-35. https://doi.org/10.1080/00131910120033628

[10] Evers, W., Tomic, W. and Browers, A. (2005) Constructive Thinking and Burnout among Secondary School Teachers. Social Psychology in Education, 8, 425-439. https://doi.org/10.1007/s11218-005-0663-8 
[11] Hakanen, J.J., Bakker, A.B. and Schaufeli, W.B. (2006) Burnout and Work Engagement among Teachers. Journal of School Psychology, 43, 495-513. https://doi.org/10.1016/j.jsp.2005.11.001

[12] Cano-Garcia, F.J., Padilla-Muñoz, E.M. and Carrasco-Ortiz, M.A. (2005) Personality and Contextual Variables in Teacher Burnout. Personality and Individual Differences, 38, 929-940. https://doi.org/10.1016/j.paid.2004.06.018

[13] Hochschild, A.R. (1983) The Managed Heart: Commercialization of Human Feeling. University of California Press, Berkeley, CA.

[14] Bono, J.E. and Vey, M.A. (2005) Toward Understanding Emotional Management at Work: A Quantitative Review of Emotional Labor Research. In: Hartel, C.E.J., Zerbe, W.J. and Ashkanasy, N.M., Eds., Emotions in Organizational Behavior, Lawrence Erlbaum Associates, Mahwah, NJ, 213-233.

[15] Diefendorff, J.M. and Richard, E.M. (2003) Antecedents and Consequences of Emotional Display Rule Perceptions. Journal of Applied Psychology, 88, 284-294. https://doi.org/10.1037/0021-9010.88.2.284

[16] Cartwright, S. and Pappas, C. (2008) Emotional Intelligence, Its Measurement and Implications for the Workplace. International Journal of Management Reviews, 10 , 149-171.

[17] Pizam, A., Jeong, G.H., Reichel, A., van Boemmel, H., Lusson, J.M., Steynberg, L. and Montmany, N. (2004) The Relationship between Risk-Taking, Sensation-Seeking, and the Tourist Behavior of Young Adults: A Cross-Cultural Study. Journal of Travel Research, 42, 251-260.

[18] Johnson, H.M. and Spector, P.E. (2007) Emotional Intelligence as a Predictor of Emotional Labor and Service Performance. Symposium at the 22nd Annual Conference of the Society for Industrial and Organizational Psychology, New York, NY.

[19] Sutton, R.E. (2007) Teachers' Anger, Frustration, and Self-Regulation. In: Schutz, P.A. and Pekrun, R., Eds., Emotions in Education, Elsevier, San Diego. https://doi.org/10.1016/B978-012372545-5/50016-2

[20] Evans, B.K. and Fischer, D.G. (1993) The Nature of Burnout: A Study of the Three-Factor Model of Burnout in Human Service and Non-Human Service Samples. Journal of Occupational and Organizational Psychology, 66, 29-38. https://doi.org/10.1111/j.2044-8325.1993.tb00514.x

[21] Zimmerman, R.D. (2008) Understanding the Impact of Personality Traits on Individuals' Turnover Decisions: A Meta-Analytic Path Model. Personnel Psychology, 61, 309-348. https://doi.org/10.1111/j.1744-6570.2008.00115.x

[22] Zellars, K.L., Perrewe, P.L. and Hochwarter, W.A. (2000) Burnout in Health Care: The Role of the Five Factors of Personality. Journal of Applied Social Psychology, 30, 1570-1598. https://doi.org/10.1111/j.1559-1816.2000.tb02456.x

[23] Schaufeli, W.B. and Bakker, A.B. (2004) Job Demands, Job Resources, and Their Relationship with Burnout and Engagement: A Multi-Sample Study. Journal of Organizational Behavior, 25, 293-315. https://doi.org/10.1002/job.248

[24] Maslach, C., Schaufeli, W.B. and Leiter, M.P. (2001) Job Burnout. Annual Review of Psychology, 52, 397. https://doi.org/10.1146/annurev.psych.52.1.397

[25] Bakker, A.B., Van Der Zee, K.I., Lewig, K.A. and Dollard, M.F. (2006) The Relationship between the Big Five Personality Factors and Burnout: A Study among Volunteer Counselors. The Journal of Social Psychology, 146, 31-50. https://doi.org/10.3200/SOCP.146.1.31-50

[26] Diefendorff, J.M., Croyle, M.H. and Gosserand, R.H. (2005) The Dimensionality 
and Antecedents of Emotional Labor Strategies. Journal of Vocational Behavior, 66, 339-357. https://doi.org/10.1016/j.jvb.2004.02.001

[27] Austin, E.J., Dore, T.C.P. and O’Donovan, K.M. (2008) Associations of Personality and Emotional Intelligence with Display Rule Perceptions and Emotional Labor. Personality and Individual Differences, 44, 679-688. https://doi.org/10.1016/j.paid.2007.10.001

[28] Shin, K.H., Lee, R., Huh, C.K. and Kim, J.Y. (2006) The Role of the 5 Big Personality Dimensions and Duty Environmental Variables in Forecasting Emotional Labor. Korean Psychology Research, 17, 355-373.

[29] Kim, H.J. (2008) Hotel Service Providers' Emotional Labor: The Antecedents and Effects on Burnout. International Journal of Hospitality Management, 27, 151-161.

[30] Grandey, A., Foo, S., Groth, M. and Goodwin, R. (2012) Free to Be You and Free to Be Me: A Climate of Authenticity Alleviates Burnout from Emotional Labor. Journal of Occupational Health Psychology, 17, 1-14. https://doi.org/10.1037/a0025102

[31] Cheung, F. and Tang, C. (2010) Effects of Age, Gender, and Emotional Labor Strategies on Job Outcomes: Moderated Mediation Analyses. Applied Psychology: Health and Wellbeing, 23, 323-39. https://doi.org/10.1111/j.1758-0854.2010.01037.x

[32] Montgomery, A., Panagopolou, E., de Wildt, M. and Meenks, R. (2006) Work-Family Interference, Emotional Labor and Burnout. Journal of Managerial Psychology, 21, 36-51. https://doi.org/10.1108/02683940610643206

[33] Beal, D.J., Trougakos, J.P., Weiss, H.M. and Green, S.G. (2006) Episodic Processes in Emotional Labour: Perceptions of Affective Delivery and Regulation Strategies. Journal of Applied Psychology, 91, 1053-1065. https://doi.org/10.1037/0021-9010.91.5.1053

[34] Naring, G., Brie't, M. and Brouwers, A. (2006) Beyond Demand-Control: Emotional Labour and Symptoms of Burnout in Teachers. Work and Stress, 20, 303-315. https://doi.org/10.1080/02678370601065182

[35] Nejat, H.B., Memduh, B. and Rukiye, Y.C. (2013) Effects of Teacher Personalities on Emotional Exhaustion: Mediating Role of Emotional Labor. Educational Sciences. Theory and Practice, 13, 1488-1496.

[36] Kiffin-Petersen, S.A., Jordan, C.L. and Soutar, G.N. (2011) The Big Five, Emotional Exhaustion and Citizenship Behaviors in Service Settings: The Mediating Role of Emotional Labor. Personality and Individual Differences, 50, 43-48. https://doi.org/10.1016/j.paid.2010.08.018

[37] Sekaran, U. (2003) Research Methods for Business. 4th Edition, John Wiley and Sons, Hoboken.

[38] Sekaran, U. (2006) Research Methods for Business: A Skill Building Approach. Wiley.

[39] Costa, P.T. and McCrae, R.R. (1985) The NEO Personality Inventory Manual. Psychological Assessment Resources, Odessa.

[40] Kruml, S.M. and Geddes, D. (2000b) Exploring the Dimensions of Emotional Labor. Management Communication Quarterly, 12, 8-49. https://doi.org/10.1177/0893318900141002

[41] Maslach, C., Jackson, S.E. and Leiter, M.P. (1996) Maslach Burnout Inventory. Manual, 3rd Edition, Consulting Psychologists Press, Mountain View.

[42] Baron, R.M. and Kenny, D.A. (1986) The Moderator-Mediator Variable Distinction in Social Psychological Research: Conceptual, Strategic, and Statistical Considera- 
tions. Journal of Personality and Social Psychology, 51, 1173-1182. https://doi.org/10.1037/0022-3514.51.6.1173

[43] Anvari, M.R.A., Kalali, N.S. and Gholipour, A. (2011) How Does Personality Affect on Job Burnout? International Journal of Trade, Economics and Finance, 2, 115.

[44] Alarcon, G., Eschleman, J.K. and Bowling, A.N. (2009) Relationship between Personality Variables and Burnout: A Meta Analysis. An International Journal of Work, Health and Organizations, 23, 244-263.

[45] Swider, B.W. and Zimmerman, R.D. (2010) Born to Burnout: A Meta-Analytic Path Model of Personality, Job Burnout, and Work Outcomes. Journal of Vocational Behavior, 76, 487-506. https://doi.org/10.1016/j.jvb.2010.01.003

[46] Goddard, R., Patton, W. and Creed, P. (2004) The Importance and Place of Neuroticism in Predicting Burnout in Employment Service Case Managers. Journal of Applied Social Psychology, 34, 282-296. https://doi.org/10.1111/j.1559-1816.2004.tb02548.x

[47] Mujtaba, B.G. (2014) Managerial Skills and Practices for Global Leadership. ILEAD Academy, Florida.

[48] Ghorpade, J., Lackritz, J. and Singh, G. (2007) Burnout and Personality: Evidence from Academia. Journal of Career Assessment, 15, 240-256.

https://doi.org/10.1177/1069072706298156

[49] Ghorpade, J., Lackritz, J. and Singh, G. (2011) Personality as a Moderator of the Relationship between Role Conflict, Role Ambiguity, and Burnout. Journal of Applied Social Psychology, 41, 1275-1298. https://doi.org/10.1111/j.1559-1816.2011.00763.x

[50] LePine, J.A., LePine, M. and Jackson, C.L. (2004) Challenge and Hindrance Stress: Relationship with Exhaustion, Motivation to Learn, and Learning Performance. Journal of Applied Psychology, 89, 883-891. https://doi.org/10.1037/0021-9010.89.5.883

[51] Tobin, R.M., Graziano, W.G., Vanman, E.J. and Tassinary, L.G. (2000) Personality, Emotional Experience, and Efforts to Control Emotions. Journal of Personality and Social Psychology, 79, 656-669. https://doi.org/10.1037/0022-3514.79.4.656

[52] Martınez-Inigo, D., Totterdell, P., Alcover, C.M. and Holman, D. (2007) Emotional Labour and Emotional Exhaustion: Interpersonal and Intrapersonal Mechanisms. Work and Stress, 21, 30-47.

[53] Halbesleben, J.R.B., Osburn, H.K. and Mumford, M.D. (2006) Action Research as a Burnout Intervention: Reducing Burnout in Federal Fire Service. Journal of Applied Behavioral Sciences, 42, 244-266. https://doi.org/10.1177/0021886305285031 